\title{
Investors' Attention Allocation to Stock Analysis: The Role of Rating Deviation
}

\author{
Yu Jin \\ Harbin Institute of Technology \\ yujin@hit.edu.cn
}

\author{
Qiang Ye \\ Harbin Institute of Technology \\ yeqiang@hit.edu.cn
}

\author{
Jingchuan $\mathrm{Pu}$ \\ Pennsylvania State University \\ pujc@psu.edu
}

\begin{abstract}
Stock analysis is important for investors. However, little is known about how investors allocate their attention to different analyses. In the last two decades, online investment communities (OICs) have proliferated. In this study, we use investors' online activities (i.e., comment and like) and amateur stock analysis in Seeking Alpha to explore how investors allocate their attention among different analyses by examining the effects of stock rating deviation on their attention. We measure the stock rating deviation of one analysis by comparing its stock rating with the previous rating for the same stock. The results show that the analyses with stock ratings that are more deviated from the existing ratings tend to receive more comments and likes from investors, indicating that rating deviation from the consensus positively impacts investor attention to stock analysis. In addition, the deviation's negativity and the stock volatility strengthen the impact of rating deviation on investor attention. However, analysts' busyness status negatively moderates this impact.
\end{abstract}

\section{Introduction}

As sophisticated market participants, stock analysts play a crucial intermediary role in discovering, disseminating, and interpreting firm disclosures $[1,2]$. A variety of studies have found that analysts provide valuable information and help investors make informed investment decisions [3-5]. Accordingly, analysts' stock analysis, generally consisting of earnings forecasts, stock ratings, and detailed analysis, has been the most important reference for investors and received significant investor attention [2].

Prior studies have provided a wealth of indirect inferences of investor attention to stock analysis via the number of analysts following a firm $[6,7]$ and the stock market reaction to analyst opinions [8, 9]. Although Lawrence, Ryans [10] examines page views of stock analysis in Yahoo! Finance and finds that investors pay more attention to stock analysis on days with earnings announcements and management guidance, providing direct evidence on investor attention to stock analysis, they regard all available analyses for a given stock as a whole and neglect to explore how investors allocate their attention among analyses, such as whether investors distribute their attention evenly across each analysis, and what analysis characteristics affect investors' attention allocation. To fill this gap, we harness the unique chance provided by online investment communities (OICs) to observe investors' attention allocation among analyses, particularly amateur stock analysis from non-official analysts who mainly depend on OICs to contribute and deliver their analyses. Existing studies suggest that similar to sell-side analysts, amateur analysts in OICs also offer valuable opinions to investors [11-13], and their stock analysis has become an essential component of analyst opinions that investors primarily rely on [14].

As attention is a scarce cognitive resource [15], investors have limited attention [16-18] and hence exhibit selective attention during information acquisition and processing [19]. The psychology literature shows that salient signals easily accessed and processed are more likely to be perceived and encoded $[15,20]$. As stock ratings representing analysts' investment advice are more salient than detailed analysis [21], investors may rely on rating-related indicators to decide which analysis to process. Given that analysts herd toward others by reducing the deviation between their rating and the consensus rating (i.e., rating deviation) [22], rating deviation can reflect how much private information analysts incorporate into their analysis[23]. In addition, it is possible that deviating ratings more informative than herding ones [24]. Due to the advantage of potential private information and the possible informativeness of deviating ratings, investors tend to regard rating deviation as an indicator of the level of analysts' private information contained in analysis and pay more investor attention to deviating ratings. That is, the rating deviation may make investors think that analyses with deviating ratings have some unique opinions or private information and thus attach more importance to them. Therefore, in this study, we 
empirically examine whether the rating deviation impacts investor attention to stock analysis. Given that analysts (the providers of private information) usually have limited private information, and that investors (the demander of private information) desire more valuable information to make informed investment decisions in an uncertain environment [25], we explore whether analysts' busyness status (i.e., analysts issue too many analyses) and the stock volatility play moderating role in the relationship between the rating deviation and investor attention. Also, given investors' negativity bias [26], we investigate the moderating effect of the deviation's negativity.

We collect a data set from Seeking Alpha (SA; seekingalpha.com), where amateur analysts release stock analysis and issue ratings for analyzed stocks. Following prior research [24], for each analysis, we use the absolute difference between its stock rating and the consensus rating to measure rating deviation. We use the total number of comments and likes received by each analysis as a proxy for how much attention investors paid. Our results show that the analyses whose stock rating deviates more from the consensus rating receive more investor attention. Furthermore, we find that the impact of rating deviation on investor attention is more pronounced when the analysis's rating deviates downward from the consensus rating and when the stock volatility is high. However, analysts' busyness status weakens this impact. The moderating effects indicate that investors adjust the intensity of depending on rating deviation to allocate attention to analyses based on the supply and demand of private information, suggesting that investors regard rating deviation as the signal of the level of private information contained in stock analysis to allocate their attention to analyses to obtain analysts' private information they needed. To validate our findings, we also conduct four robustness checks and obtain similar results.

Our study contributes to the academic literature in the following aspects. First, we provide new insights into the literature on investor attention to stock analysis. Prior research has explored investor attention to stock analysis by treating all analyses for each stock as a whole [10]. We move further from this research by examining investor attention specific to individual stock analysis and considering the role of analysis characteristics. Second, we extend the literature on the impacts of analysts' herding behavior. Prior research has focused on its influence on analysts' performance $[24,27,28]$ and the stock market $[22,29,30]$, but we turn our sight to its effects on investor attention. Third, we enrich the research on analysts' decision fatigue. Prior studies have provided evidence of analysts' decision fatigue, and find that decision fatigue leads to less accurate and timely earnings forecasts and stock ratings [31, 32]. We test how investors respond to analysts' decision fatigue, and the results show that investors rely less on rating deviations to allocate their attention to amateur analysis when the analysis is issued by a busy analyst. The findings provide evidence on the effects of analysts' decision fatigue on investors' information choices.

\section{Hypotheses}

\subsection{The impact of rating deviation on investor attention}

Kahneman [15] states that attention is a scarce cognitive resource, and individuals have limited attention. Due to attention constraints, individuals cannot notice everything, particularly in an information-rich economy [33]. Miller [34] shows that individuals usually only remember about seven items when processing information, which leads to deficits in information processing capabilities. Extensive research has consistently reported that investors suffer from limitations of attention and information processing capabilities [35-37]. For example, investors are unable to fully process Friday earnings announcements [16] and merger announcements [18], as their limited attention is occupied by other activities.

Given the limitation of information processing power caused by attention constraints, faced with a wealth of available information, investors tend to be selective in information acquisition and processing $[19,38]$. The psychology literature suggests that individuals must first perceive and encode information as a mental representation in the brain before processing and understanding it [39]. As perception and encoding information requires attention and effort, individuals are more likely to focus directly on signals that are easily accessible and processed, i.e., salient signals [20]. In the context of stock analysis, stock ratings are more salient relative to detailed stock analysis, as they provide direct investment advice, suggesting investors buy, hold, or sell a given stock [21]. Bearing the above in mind, investors may depend on stock ratings to decide whether to pay attention to stock analysis.

According to the herding theory [22], analysts tend to mimic others and issue herding ratings when having little private information, and instead, they will hold on to their views and release ratings that deviate more from the consensus rating if their private information is superior and overwhelming. As a result, analyses with deviating ratings contain more private 
information than those with herding ratings. In addition, deviating ratings have been found to be more informative than herding ones [24]. In the context of OICs, where all analyses for each stock are integrated into one specific page, investors can compare each analysis's stock rating with others directly and estimate its deviation from the consensus rating easily. As a result, considering the advantage of private information and the informativeness of deviating ratings, investors may regard rating deviation as the signal of the level of private information contained in stock analysis and pay more attention to analyses with larger rating deviations to pursue private information. Therefore, we formulate our first hypothesis:

Hypothesis 1 (H1): The stock analysis whose stock rating deviates more from the consensus rating receives more investor attention.

\subsection{The moderating role of rating deviation's negativity}

Research in behavioral finance has found that investors exhibit negativity bias. Investors have different responses to good news and bad news [26, 40]. In particular, they react more strongly to bad news than good news [26]. Moreover, individuals have stronger evaluative reactions to negative information than positive information, even when they are equally probable and equally extreme [41].

When the stock analysis has a negative rating deviation (i.e., its rating deviates downward from the consensus rating), it implies that the analyst has a more negative expectation of the stock returns than others. Due to the negativity bias, investors may strengthen their reactions to the analyses with negative rating deviations. Given the role of rating deviation in investors' attention allocation, the negativity of rating deviation may motivate investors to rely more on deviation to allocate attention to stock analysis. In contrast, if stock analysis's rating deviates upward from the consensus rating, the more positive expectation of the stock returns will weaken investors' response to this analysis. In addition, as fake news exists in the OICs [14], investors are likely to suspect analysts who issue positive deviating ratings to obtain compensation from public companies. As a result, the impact of rating deviation on investor attention becomes weaker when the rating deviates upward from the consensus. This leads to our second hypothesis:

Hypothesis 2 (H2): The deviation's negativity positively moderates the relationship between rating deviation of stock analysis and investor attention.

\subsection{The moderating role of analyst's busyness status}

Baumeister, Bratslavsky [42] show that decision quality declines after devoting effort to make complex decisions in a given time due to the draining of mental resources, a phenomenon known as decision fatigue. Decision fatigue is a universal phenomenon, and several studies document decision fatigue in various settings. Hirshleifer, Levi [31] show that sell-side analysts issuing too many earnings forecasts in a given time become decision fatigue, and their forecast accuracy declines, since analyzing stock value is a slow and rigorous reasoning process that requires mental resources. Similarly, for busy amateur analysts who contribute too much analysis within a given time, their resulting draining of mental resources will lead to decision fatigue and temporarily reduce the quality of the subsequent stock analysis. As a result, investors are more cautious about the opinions of busy analysts than those of not-busy analysts.

In addition, private information is based on the acquisition and the analytical ability of stock-relevant information. An individual's private information is limited. If analysts are in the status of busyness, it is inevitable to distribute very little private information into each analysis. In particular, their analyses with larger rating deviations are unlikely to be high quality and driven by the sufficient possession of private information. Therefore, rating deviation cannot reflect the level of private information contained in stock analysis that is from busy analysts, and thus investors may rely less on rating deviations to allocate attention.

On the contrary, if analysts are not busy, they are free from decision fatigue and with fewer information constraints. In such a context, amateur analysts have enough time and mental resources to reasoning the stock value and rationally choose to herd towards the consensus or not based on an objective estimation of the possession of private information. As a result, the rating deviation is a trustworthy and reliable signal reflecting information content. Accordingly, investors put more weight on the rating deviation to evaluate the informativeness of analysis when allocating their attention. Thus, we propose our third hypothesis:

Hypothesis 3 (H3): Amateur analyst's busyness status negatively moderates the relationship between rating deviation of stock analysis and investor attention.

\subsection{The moderating role of stock's volatility}

Historical volatility is a statistical measure of the dispersion of returns for a given stock over a given period of time. Volatility is usually related to 
uncertainty or risk. Due to the uncertainty and risk, investors demand more information to make informed investment decisions. Given the finding that deviating stock analysis generally contains more analysts' private information[23], investors are more likely to pay attention to deviating rating when stock volatility is high. As a result, stock volatility may positively moderate the relationship between the deviation and investor attention.

Hypothesis 4 (H4): Stock volatility positively moderates the relationship between rating deviation of stock analysis and investor attention.

\section{Methodology}

\subsection{Data source}

The primary data for this study comes from Seeking Alpha (SA), a leading OIC in the stock analysis market, with 40 million monthly user visits. In this study, we focus only on the constituent stocks of the Standard \& Poor's 500 index (S\&P 500). We select these stocks because they cover a broad range of industries and represent over half of the market capitalization of the entire U.S. stock market. In addition, most of them attract many amateur analysts and investors to analyze and discuss them in SA.

We collect all the analyses for each stock issued between March 6, 2019 and Jan 05, 2021. Some of them discuss multiple stocks simultaneously, causing some difficulties in distributing investor attention to each stock-analysis combination. To measure investor attention accurately, we focus only on 15,070 singlestock analyses in this study. The information on each analysis includes analysis ID, analysis content, publication date, analyst ID, stock ticker, stock rating, comments, and likes. Similar to sell-side ratings, the five possible stock ratings are "Very Bullish", "Bullish", "Neutral", "Bearish", and "Very Bearish", we convert them into numerical scores $(5,4,3,1$, and 1) to quantify ratings issued by amateur analysts. We also collect each analyst's personal information and release history.

For the stocks in our sample, we collect financial market data from the Center for Research in Security Prices (CRSP) and sell-side analyst data from the Institutional Brokers' Estimate System (I/B/E/S), respectively. In order to interpret easily, we reverse IBES rating codes so that " 1 " corresponds to "Strong Sell" and "5" corresponds to "Strong Buy". We exclude stock-analysis observations that lack stockspecific characteristics. To ensure a sufficient number of amateur analysts and investors to analyze and discuss them, we only retain the stocks that have more than 20 analyses in our study period. These criteria leave us with a final sample of 9,068 stock-analysis observations.

\subsection{Variable descriptions}

In this study, we use the total number of comments and likes received by each stock analysis to measure investor attention (Attention). In addition to writing comments to discuss with analysts, interested investors may click the "Likes" button to give feedback, especially when they support the views contained in an analysis. In other words, both commenting and liking reflect that investors have paid attention to this analysis. According to the finance literature, stock-related information is time-sensitive, and the analysis of fundamentals generally predicts future three-month stock returns [11]. As a result, investors usually pay no attention to opinions posted more than three months ago when seeking advice for their investment decisions. Therefore, we classify comments made after 90 days as ex-post attention. Since we are interested in investor attention in the information acquisition process, we exclude all expost investor attention. Unfortunately, we cannot rule out ex-post likes since there is no available data on the timing of clicking the "Likes" button. Therefore, we use the number of comments received by stock analysis as another proxy for investor attention in robustness checks.

Following Palmon, Sarath [24], for each analysis, we use the absolute difference between its stock rating and the consensus rating to represent its rating deviation (AbsDeviation). Since analysts have limited attention [32], they only refer to a certain amount of analyses when herding toward others. In addition, they also consider the activeness of the analysis. Therefore, we follow two rules in the calculation of the consensus rating. First, we select a reasonable visual range and average only the included stock analyses. SA presents 10 of the most recent ratings on the first screen. As a result, investors pay attention to at least 10 ratings. In addition, individuals usually notice limited items when processing information[34]. We thus set this range as 15 analyses and verify the results with 10 and 20 in the robustness checks. Second, we choose 90 days as an effective time interval to screen out stale opinions and retain active ones. In particular, if no less than 15 analyses are issued within 90 days before the analysis release, the consensus is the average of the latest 15 ratings. Otherwise, we average all ratings within the last 90 days.

To test $\mathrm{H} 2, \mathrm{H} 3$, and $\mathrm{H} 4$, we introduce three moderators. The first one is Negativity, indicating deviation's negativity. It equals one if the analysis's stock rating deviates downward from the consensus 
rating; otherwise, it equals zero. The second moderator is Busyness, reflecting an analyst's busyness status. In particular, it equals one if the analyst issues no less than 10 analyses within 30 days before releasing the analysis, and zero otherwise. We use 10 analyses to judge whether an analyst is in the busy status is because the mean and median of the number of articles analysts issued within 30 days are 8 and 11.5. Although Busyness can also serve as a proxy for the quality of writer, it is less likely the case in the OIC because the purpose of analysts is to provide accurate analysis and more busy analysts are more likely have expressed their private information before which leads to a less valuable analysis. The third moderator is the past stock return volatility, and we use the standard deviation of daily returns over the past month to measure Volatility.

We control for a host of amateur analyst-, analysis-, and stock-specific characteristics related to investor attention. In particular, we control for Words, Figures, Analytic, and Clout to consider the effects of the general quality of analysis or the amount of effort exerted by the analysts on investor attention. Table 1 defines all variables used in this paper. Here, $t$ denotes the day when the analysis is released. In the calculation of abnormal returns, if the analysis was issued on a weekend or holiday, day $t$ corresponds to the following trading day.

Table 1 Variable Descriptions

\begin{tabular}{|c|c|c|}
\hline Variable & Description & Source \\
\hline \multicolumn{3}{|c|}{ Dependent Variable } \\
\hline Attention & The number of comments and likes received by the stock analysis. & SA \\
\hline \multicolumn{3}{|c|}{ Independent variable } \\
\hline AbsDeviation & The absolute difference between the analysis's stock rating and the consensus rating. & SA \\
\hline \multicolumn{3}{|c|}{ Moderator Variables } \\
\hline Negativity & A dummy variable indicating whether the analysis's stock rating deviates downward from the consensus rating. & SA \\
\hline Busyness & $\begin{array}{l}\text { A dummy variable indicating whether the analysts is busy. In particular, it equals one if the analyst issues no less than } \\
10 \text { analyses within } 30 \text { days before releasing the analysis, and zero otherwise. }\end{array}$ & SA \\
\hline Volatility & The standard deviation of daily returns over days $[t-30, t-1]$. & CRSP \\
\hline \multicolumn{3}{|c|}{ Control Variables } \\
\hline MonthsOnSA & The number of months between her/his first analysis and the stock analysis for the analyst. & SA \\
\hline Marketplace & A dummy variable indicating whether the analyst provides "Marketplace" service. & SA \\
\hline Words & The number of words in the analysis. & SA \\
\hline Figures & The number of tables and figures in the analysis. & SA \\
\hline Analytic & $\begin{array}{l}\text { The degree to which the analyst uses words that suggest formal, logical, and hierarchical thinking patterns in the } \\
\text { analysis, coded by LIWC. }\end{array}$ & SA \\
\hline Clout & $\begin{array}{l}\text { The relative social status, confidence, or leadership that the analyst displays through their writing in the analysis, coded } \\
\text { by LIWC. }\end{array}$ & SA \\
\hline Analyses & The number of analyses for the stock on day $t$. & SA \\
\hline EADate0 & A dummy variable indicating whether the analysis is published on the earnings announcement date. & $\mathrm{I} / \mathrm{B} / \mathrm{E} / \mathrm{S}$ \\
\hline EADatel & A dummy variable indicating whether the analysis is published on the first day after earnings announcement date. & $\mathrm{I} / \mathrm{B} / \mathrm{E} / \mathrm{S}$ \\
\hline EADate2 & A dummy variable indicating whether the analysis is published on the second day after earnings announcement date. & $\mathrm{I} / \mathrm{B} / \mathrm{E} / \mathrm{S}$ \\
\hline EADate3 & A dummy variable indicating whether the analysis is published on the third day after earnings announcement date. & $\mathrm{I} / \mathrm{B} / \mathrm{E} / \mathrm{S}$ \\
\hline MGDate0 & A dummy variable indicating whether the analysis is published on the management guidance date. & $\mathrm{I} / \mathrm{B} / \mathrm{E} / \mathrm{S}$ \\
\hline MGDate1 & A dummy variable indicating whether the analysis is published on the first day after management guidance date. & $\mathrm{I} / \mathrm{B} / \mathrm{E} / \mathrm{S}$ \\
\hline MGDate2 & A dummy variable indicating whether the analysis is published on the second day after management guidance date. & $\mathrm{I} / \mathrm{B} / \mathrm{E} / \mathrm{S}$ \\
\hline MGDate3 & A dummy variable indicating whether the analysis is published on the third day after management guidance date. & $\mathrm{I} / \mathrm{B} / \mathrm{E} / \mathrm{S}$ \\
\hline IBESDispersion & The standard deviation of sell-side ratings within 90 days prior to the analysis release. & $\mathrm{I} / \mathrm{B} / \mathrm{E} / \mathrm{S}$ \\
\hline IBESRating & The average of sell-side ratings within 90 days prior to the analysis release. & $\mathrm{I} / \mathrm{B} / \mathrm{E} / \mathrm{S}$ \\
\hline ARet $_{t-1}$ & Value-weighted market-adjusted return on day $t-1$. & CRSP \\
\hline ARet $_{t-2}$ & Value-weighted market-adjusted on day $t-2$. & CRSP \\
\hline $\operatorname{ARet}_{[t-60, t-3]}$ & Value-weighted market-adjusted buy-and-hold return over days $[t-60, t-3]$. & CRSP \\
\hline Weekend & A dummy variable indicating whether the analysis is released on a weekend. & \\
\hline
\end{tabular}

\subsection{Research model}

To explore whether stock analysis's rating deviation affects investor attention, we estimate the regression of investor attention on rating deviation and a series of controls, as presented in the following equation:

$$
\begin{aligned}
\log (\text { Attention }) & =\alpha_{0}+\alpha_{1} \text { AbsDeviation } \\
& +\alpha_{2} \text { Controls }+\alpha_{3} \text { Stock }+\alpha_{4} \text { Week }+\varepsilon
\end{aligned}
$$

Stock denotes the stock fixed effects, and Week denotes the week fixed effects. To address skewness 
in some variable distributions, we take natural logarithms of Variable plus 1, denoting Log(Variable). Variable includes Attention, MonthsOnSA, Words, Figures, and Analyses. The regression is estimated by ordinary least squares (OLS) with robust standard errors. According to $\mathrm{H} 1$, the coefficient on AbsDeviation ( $\left.\alpha_{1}\right)$ is expected to be significantly positive.

\section{Empirical analyses and results}

\subsection{Descriptive statistics}

Before moving on to our empirical results, we first present some descriptive information about all the variables in Table 2. We can observe that the minimum of Attention is 0, while its maximum is 2,407, suggesting that stock analysis generates different investor attention. Statistics for Negativity show that $41.7 \%$ of the analyses deviate downward from the consensus. On average, amateurs appear to exert great efforts to contribute analyses since these analyses include a fair amount of tables and figures (the mean of Figures is 5.561). In addition, both the correlation matrix and Variance Inflation Factor (VIF) tests indicate that multicollinearity is not dominant across our explanatory variables [43, 44].

Table 2. Descriptive Statistics

\begin{tabular}{|c|c|c|c|c|c|}
\hline & Mean & Std. Dev. & Min & Median & Max \\
\hline Attention & 68.475 & 92.359 & 0.000 & 40.000 & 2407.000 \\
\hline AbsDeviation & 0.715 & 0.577 & 0.000 & 0.600 & 4.000 \\
\hline Negativity & 0.417 & 0.493 & 0.000 & 0.000 & 1.000 \\
\hline Busyness & 0.395 & 0.489 & 0.000 & 0.000 & 1.000 \\
\hline Volatility & 0.027 & 0.020 & 0.005 & 0.021 & 0.158 \\
\hline MonthsOnSA & 64.807 & 39.856 & 0.000 & 63.667 & 174.967 \\
\hline Marketplace & 0.433 & 0.495 & 0.000 & 0.000 & 1.000 \\
\hline Words & 1533.661 & 773.168 & 47.000 & 1350.000 & 11711.000 \\
\hline Figures & 5.561 & 5.070 & 0.000 & 5.000 & 91.000 \\
\hline Analytic & 92.769 & 5.717 & 36.010 & 94.380 & 99.000 \\
\hline Clout & 52.917 & 9.106 & 22.930 & 52.070 & 88.230 \\
\hline Analyses & 1.346 & 0.705 & 1.000 & 1.000 & 7.000 \\
\hline EADate0 & 0.028 & 0.166 & 0.000 & 0.000 & 1.000 \\
\hline EADatel & 0.043 & 0.204 & 0.000 & 0.000 & 1.000 \\
\hline EADate2 & 0.028 & 0.164 & 0.000 & 0.000 & 1.000 \\
\hline EADate3 & 0.023 & 0.149 & 0.000 & 0.000 & 1.000 \\
\hline MGDate0 & 0.010 & 0.101 & 0.000 & 0.000 & 1.000 \\
\hline MGDate1 & 0.015 & 0.121 & 0.000 & 0.000 & 1.000 \\
\hline MGDate2 & 0.010 & 0.099 & 0.000 & 0.000 & 1.000 \\
\hline MGDate3 & 0.009 & 0.093 & 0.000 & 0.000 & 1.000 \\
\hline IBESDispersion & 0.709 & 0.404 & 0.000 & 0.707 & 2.121 \\
\hline IBESRating & 3.452 & 0.577 & 1.500 & 3.500 & 5.000 \\
\hline $\operatorname{ARet}_{t-1}$ & -0.000 & 0.031 & -0.459 & -0.000 & 0.420 \\
\hline $\operatorname{ARet}_{t-2}$ & -0.001 & 0.029 & -0.426 & -0.000 & 0.270 \\
\hline $\operatorname{ARet}_{[t-60, t-3]}$ & -0.011 & 0.172 & -0.646 & -0.010 & 2.420 \\
\hline Weekend & 0.088 & 0.283 & 0.000 & 0.000 & 1.000 \\
\hline
\end{tabular}

\subsection{Main analyses}

Table 3 presents the estimated results of the effects of rating deviation on investor attention. As presented in Column (2), the estimated coefficient on AbsDeviation is significantly positive $(0.167)$ at the $1 \%$ level. The results provide strong support for $\mathrm{H} 1$; that is, the stock analysis whose stock rating deviates more from the consensus rating receives more investor attention. The coefficient estimates on the control variables in Columns (1) and (2) are generally consistent with our expectations. The negative coefficient estimates on $\log ($ Analyses $)$ imply that investors allocate less attention to each one if there are too many analyses on the same day, providing evidence of investors' limited attention. Interestingly, we find that IBESDispersion has a positive impact on investor attention to amateur analysis. The results suggest that when investors cannot obtain consistent investment advice from sell-side analysts, they resort to amateur analysts. Hence, this provides evidence that amateurs supplement sell-side information for investors and confirms that investors harness amateur analysis because of their information demand [12]. The coefficient estimates on Weekend are positive and significant, inconsistent with the notion that investors have more severe attention constraints on weekends. The inconsistency is due to the lack of analyses these days.

We further explore the moderating roles. To avoid multicollinearity, we center all the independent variables and the moderators before interacting them [45]. As indicated the Column (3) of Table 3, there are positive and significant coefficients on AbsDeviation $\times$ Negativity and AbsDeviation $\times$ Volatility. The results suggest that the deviation's negativity and the volatility of stock returns strengthen the impacts of rating deviation on investor attention, supporting $\mathrm{H} 2$ and $\mathrm{H} 4$. In addition, there is a negative and significant coefficient on AbsDeviation $\times$ Busyness. The result suggests that the analyst's busyness status weakens the impacts of rating deviation on investor attention, supporting $\mathrm{H} 3$.

\subsection{Robustness Checks}

We conduct several robustness checks to validate our results. First, we concern potential issues from using 15 analyses to measure consensus rating and thus we consider two alternative measures of AbsDeviation by adjusting the range of vision. The first measure (AbsDeviation 10) narrows it to the latest 10 ratings. The second measure magnifies it to the latest 20 ratings (AbsDeviation 20). We then redo our analysis with them to further check our findings. As 
Panel A and B in Tables 4 indicated, our measures of rating deviation do not induce the sensitivity of our results.

Table 3. Main Analyses

\begin{tabular}{|c|c|c|c|}
\hline & (1) & $(2)$ & (3) \\
\hline AbsDeviation & & $\begin{array}{l}0.167^{* * *} \\
(0.01)\end{array}$ & $\begin{array}{l}0.140^{* * *} \\
(0.02)\end{array}$ \\
\hline AbsDeviation $\times$ Negativity & & & $\begin{array}{l}0.087^{* * *} \\
(0.03)\end{array}$ \\
\hline AbsDeviation $\times$ Busyness & & & $\begin{array}{l}-0.055^{* *} \\
(0.03)\end{array}$ \\
\hline AbsDeviation $\times$ Volatility & & & $\begin{array}{l}1.897^{* * *} \\
(0.61)\end{array}$ \\
\hline Negativity & $\begin{array}{l}-0.046^{* * *} \\
(0.02)\end{array}$ & $\begin{array}{l}-0.082^{* * *} \\
(0.02)\end{array}$ & $\begin{array}{l}-0.084^{* * *} \\
(0.02)\end{array}$ \\
\hline Busyness & $\begin{array}{l}-0.058^{* * *} \\
(0.02)\end{array}$ & $\begin{array}{l}-0.056^{* * *} \\
(0.02)\end{array}$ & $\begin{array}{l}-0.054^{* * *} \\
(0.02)\end{array}$ \\
\hline Volatility & $\begin{array}{l}3.687^{* * *} \\
(0.54)\end{array}$ & $\begin{array}{l}4.026^{* * *} \\
(0.53)\end{array}$ & $\begin{array}{l}4.024^{* * *} \\
(0.53)\end{array}$ \\
\hline MonthsOnSA & $\begin{array}{l}0.071^{* * *} \\
(0.01)\end{array}$ & $\begin{array}{l}0.074^{* * *} \\
(0.01)\end{array}$ & $\begin{array}{l}0.075^{* * *} \\
(0.01)\end{array}$ \\
\hline Marketplace & $\begin{array}{l}0.095^{* * *} \\
(0.02)\end{array}$ & $\begin{array}{l}0.072^{* * *} \\
(0.02)\end{array}$ & $\begin{array}{l}0.073^{* * *} \\
(0.02)\end{array}$ \\
\hline Words & $\begin{array}{l}0.213^{* * *} \\
(0.02)\end{array}$ & $\begin{array}{l}0.224^{* * *} \\
(0.02)\end{array}$ & $\begin{array}{l}0.225^{* * *} \\
(0.02)\end{array}$ \\
\hline Figures & $\begin{array}{l}0.113^{* * *} \\
(0.01)\end{array}$ & $\begin{array}{l}0.108^{* * *} \\
(0.01)\end{array}$ & $\begin{array}{l}0.109^{* * *} \\
(0.01)\end{array}$ \\
\hline Analytic & $\begin{array}{l}-0.014^{* * *} \\
(0.00)\end{array}$ & $\begin{array}{l}-0.014^{* * *} \\
(0.00)\end{array}$ & $\begin{array}{l}-0.014^{* * *} \\
(0.00)\end{array}$ \\
\hline Clout & $\begin{array}{l}-0.004^{* * *} \\
(0.00)\end{array}$ & $\begin{array}{l}-0.004^{* * *} \\
(0.00)\end{array}$ & $\begin{array}{l}-0.004^{* * *} \\
(0.00)\end{array}$ \\
\hline Analyses & $\begin{array}{l}-0.377^{* * *} \\
(0.04)\end{array}$ & $\begin{array}{l}-0.383^{* * *} \\
(0.03)\end{array}$ & $\begin{array}{l}-0.385^{* * *} \\
(0.03)\end{array}$ \\
\hline EADate0 & $\begin{array}{l}0.094^{*} \\
(0.05)\end{array}$ & $\begin{array}{l}0.106^{* *} \\
(0.05)\end{array}$ & $\begin{array}{l}0.104^{* *} \\
(0.05)\end{array}$ \\
\hline EADate1 & $\begin{array}{l}0.087^{* *} \\
(0.04)\end{array}$ & $\begin{array}{l}0.094^{* *} \\
(0.04)\end{array}$ & $\begin{array}{l}0.100^{* *} \\
(0.04)\end{array}$ \\
\hline EADate2 & $\begin{array}{l}0.113^{* *} \\
(0.05)\end{array}$ & $\begin{array}{l}0.105^{* *} \\
(0.05)\end{array}$ & $\begin{array}{l}0.101^{* *} \\
(0.05)\end{array}$ \\
\hline EADate3 & $\begin{array}{l}-0.053 \\
(0.05)\end{array}$ & $\begin{array}{l}-0.032 \\
(0.05)\end{array}$ & $\begin{array}{l}-0.027 \\
(0.05)\end{array}$ \\
\hline MGDate0 & $\begin{array}{l}-0.088 \\
(0.09)\end{array}$ & $\begin{array}{l}-0.096 \\
(0.09)\end{array}$ & $\begin{array}{l}-0.099 \\
(0.09)\end{array}$ \\
\hline MGDate1 & $\begin{array}{l}-0.033 \\
(0.06)\end{array}$ & $\begin{array}{l}-0.021 \\
(0.06)\end{array}$ & $\begin{array}{l}-0.027 \\
(0.06)\end{array}$ \\
\hline MGDate 2 & $\begin{array}{l}-0.131 \\
(0.09)\end{array}$ & $\begin{array}{l}-0.114 \\
(0.09)\end{array}$ & $\begin{array}{l}-0.107 \\
(0.09)\end{array}$ \\
\hline MGDate3 & $\begin{array}{l}0.107 \\
(0.09)\end{array}$ & $\begin{array}{l}0.093 \\
(0.09)\end{array}$ & $\begin{array}{l}0.088 \\
(0.09)\end{array}$ \\
\hline IBESDispersion & $\begin{array}{l}0.055^{* * *} \\
(0.02)\end{array}$ & $\begin{array}{l}0.053^{* * *} \\
(0.02)\end{array}$ & $\begin{array}{l}0.053^{* * *} \\
(0.02)\end{array}$ \\
\hline IBESRating & $\begin{array}{l}-0.079^{* * *} \\
(0.02)\end{array}$ & $\begin{array}{l}-0.075^{* * *} \\
(0.02)\end{array}$ & $\begin{array}{l}-0.073^{* * *} \\
(0.02)\end{array}$ \\
\hline $\operatorname{ARet}_{t-1}$ & $\begin{array}{l}-1.121^{* * *} \\
(0.23)\end{array}$ & $\begin{array}{l}-1.068^{* * *} \\
(0.22)\end{array}$ & $\begin{array}{l}-1.059^{* * *} \\
(0.23)\end{array}$ \\
\hline ARet $_{t-2}$ & $\begin{array}{l}-0.528^{* *} \\
(0.25)\end{array}$ & $\begin{array}{l}-0.467^{*} \\
(0.24)\end{array}$ & $\begin{array}{l}-0.439^{*} \\
(0.24)\end{array}$ \\
\hline $\operatorname{ARet}_{[t-60, t-3]}$ & $\begin{array}{l}-0.584^{* * *} \\
(0.05)\end{array}$ & $\begin{array}{l}-0.569^{* * *} \\
(0.05)\end{array}$ & $\begin{array}{l}-0.578^{* * *} \\
(0.05)\end{array}$ \\
\hline Weekend & $\begin{array}{l}0.229^{* * *} \\
(0.03)\end{array}$ & $\begin{array}{l}0.227^{* * *} \\
(0.03)\end{array}$ & $\begin{array}{l}0.228^{* * *} \\
(0.03)\end{array}$ \\
\hline Constant & $\begin{array}{l}3.845^{* * *} \\
(0.26)\end{array}$ & $\begin{array}{l}3.656^{* * *} \\
(0.25)\end{array}$ & $\begin{array}{l}3.586^{* * *} \\
(0.25)\end{array}$ \\
\hline Stock \& Week FE & YES & YES & YES \\
\hline Observations & 9,068 & 9,068 & 9,068 \\
\hline Adjusted $R^{2}$ & 0.635 & 0.642 & 0.643 \\
\hline
\end{tabular}

Table 4 Robustness Checks

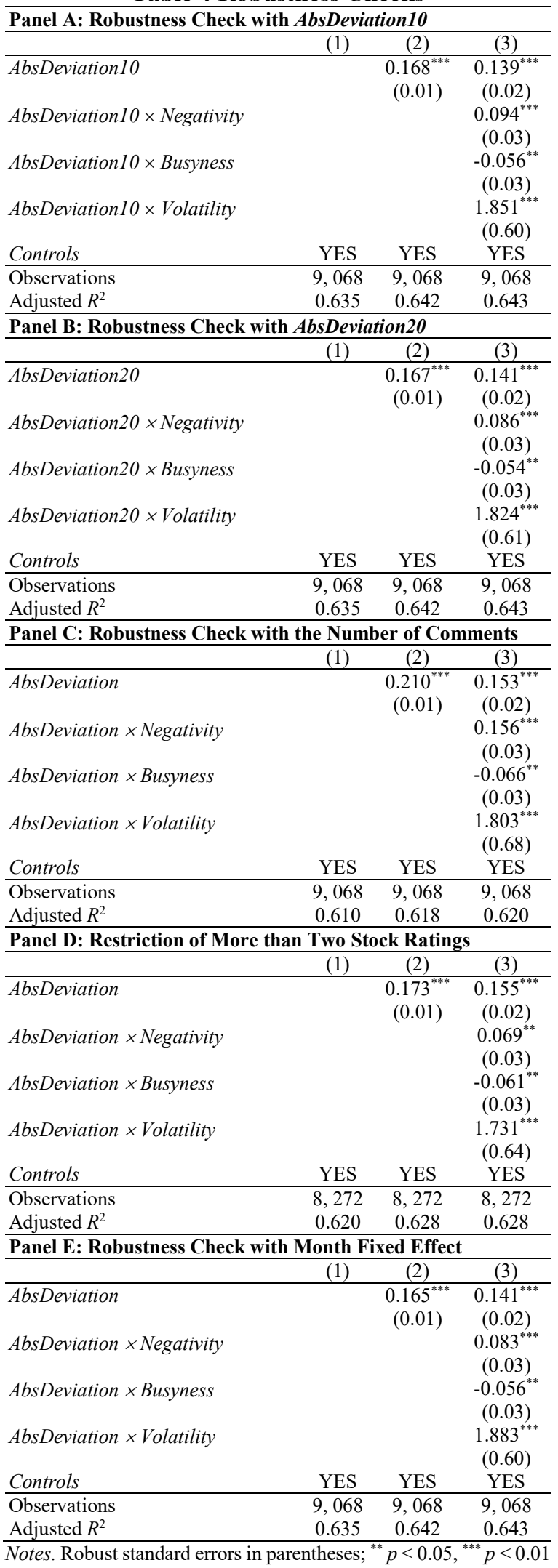


Second, we only use the number of comments as a proxy of investor attention instead of the total number of comments and likes. The results reported in Panel $\mathrm{C}$ are similar to prior ones. Besides, to alleviate the concerns that controversial articles may arouse intense discussion, which leads to that the total number of comments may overestimate attention, we use the number of unique investors writing comments for articles as a proxy of investor attention, and our results are robust.

Third, to calculate the consensus rating more reasonably, we delete the observations when there are less than three stock ratings. As reported by Panel D, the results are largely consistent with the main results.

Fourth, we use month fixed effects instead of week fixed effects in the models. The results reported in Panel E are similar to prior ones, further indicating the robustness of our main results. Also, to control unobserved analyst-related variables that might influence investor attention, we consider author fixed effect in our model. Also, to further validate our result, we adopt a more rigorous stock-yearmonth fixed effect. The results consistently indicate the positive effects of rating deviation on investor attention.

\section{Discussion}

In this paper, we explore how rating deviation impacts investor attention to stock analysis. Through a series of empirical analyses, we obtain several important findings. First, rating deviation has a positive impact on investor attention. It means that investors distribute their attention unevenly across each analysis, and to pursue more analysts' private information, they pay more attention to analyses whose stock ratings deviate more from the consensus rating. The results confirm that due to limited attention, investors exhibit attentional preferences when allocating attention to information [19]. Kadous, Mercer [46] show that under experimental conditions, the deviating information increases investors' willingness to choose and acquire. We extend this finding by providing empirical evidence that the effect exists in investors' actual information acquisition.

Second, the impact of rating deviation on investor attention is more pronounced when the rating deviates downward from the consensus rating. This suggests that the deviations' negativity enhances investors' attentional preference for analyses with deviating ratings. Our findings confirm investors' negativity bias [26, 40, 41]. Moreover, we find that the rating deviation has a more pronounced impact on investor attention when stock volatility is high. The results suggest that when the stock price is uncertain, investors intensify their preferences to deviating ratings due to the larger demand for private information. Furthermore, we find that investors discount the attention allocation to the stock analysis with deviating ratings that are issued by a busy analyst, indicating that investors are able to recognize analysts' decision fatigue and concerns the level of private information contained in these analyses. The analyses on the moderators examine the mechanisms: the readers perceive whether the analyst has unique opinions and private information through the rating deviation.

\subsection{Theoretical Contributions}

Our study makes theoretical contributions in the following three aspects. First, we provide new insights into investor attention to stock-related information. Previous studies have mainly focused on how investors allocate attention to certain types of information, such as portfolio information [47], SEC filings [48], accounting information [25], and stock analysis [10]. Our study continues to investigate investor attention to stock analysis. However, unlike prior research, we leverage the OICs and examine investor attention specific to individual stock analysis instead of regarding all analyses for each stock as a whole [10]. In addition, to measure investor attention, some prior research assumes that investors should pay attention to the information exposed to them [49-51]. However, this assumption is overstrict [52]. In this study, we use the number of comments received by each analysis to measure investor attention. This measure identifies the information that investors actively seek and acquire. Therefore, it not only captures investor attention at the individual analysis level, but also guarantees the authenticity of attention.

Second, we extend the literature on the impacts of analysts' herding behavior. Previous studies have found its influence on analysts' performance $[24,27$, $28]$ and the stock market $[22,29,30]$. However, as information intermediaries, analysts play a role in producing and delivering investment advice for investors in the stock market [11-13]. Therefore, their herding behavior inevitably affects investor reaction. We expand prior research by considering another impact, investors' attention allocation to stock analysis. We present empirical evidence on the effects of amateurs' herding behavior on investor attention.

Finally, this study adds to recent research on analysts' decision fatigue. Prior studies have provided the evidence of analysts' decision fatigue, and find that decision fatigue leads to less accurate and timely earnings forecast and stock ratings [31,32]. We test how investors respond to analysts' decision fatigue. Our results show that investors rely less on rating 
deviations to allocate their attention to amateur analysis when the analysis is from a busy analyst. The findings provide evidence on the effects of analysts' decision fatigue on investors' information choice.

\subsection{Practical Implications}

The results of this research provide important implications for both amateur analysts and community owners. Given the development of amateur analysis, it is crucial to understanding how investors allocate their attention across analyses. Specifically, we have found that analyses with deviating ratings attract more investor attention. This result suggests that investors regard rating deviations as a signal reflecting the level of analysts' unique opinion or private information and thus attach more importance to deviating opinions. Community owners should build some mechanisms to motivate amateur analysts to share deviating opinions. For example, they can introduce monetary or nonmonetary incentive programs to reward analysts who voice differently. In addition, communities should display the consensus rating after each stock rating. This change will grant investors greater access to rating deviations. As a result, communities will indirectly punish analysts' herding behavior and promote deviating opinions.

\subsection{Limitations and Future Research}

Our study has two limitations. First, our sample only covers the S\&P 500 component stocks, and our study period only encompasses less than two years. Future research should increase the number of stocks and extend the study period to generalize our results. Additionally, future work could explore the determinants of amateurs' herding behavior. We also call for studies to investigate how the deviating analyses affect the stock market.

\section{Conclusion}

In this study, we use a novel data set in OIC to study how investors allocate attention among analyses. The results show that the analyses whose rating deviates more from the consensus rating receive more investor attention, indicating that the rating deviation has a positive impact on investor attention. In addition, the deviation's negativity and the stock volatility positively moderate the relationship between rating deviation and investor attention, and however, analysts' busyness status negatively moderates this relationship. Our findings enrich the understandings of investors' attention allocation to stock analysis and have implications for amateur analysts and community owners sharing more deviating opinions, thereby meeting investors' information demand.

\section{Acknowledgements}

The authors would like to thank the editor and reviewers for their helpful and constructive suggestions. This research was supported by the National Natural Science Foundation of China (Grant \# 71850013 and 71801063).

\section{References}

[1] Huang, A.H., et al., Analyst information discovery and interpretation roles: A topic modeling approach. Management Science, 2018. 64(6): p. 2833-2855.

[2] Chen, X., Q. Cheng, and K. Lo, On the relationship between analyst reports and corporate disclosures: Exploring the roles of information discovery and interpretation. Journal of Accounting \& Economics, 2010. 49(3): p. 206-226.

[3] Fried, D. and D. Givoly, Financial analysts' forecasts of earnings: A better surrogate for market expectations. Journal of Accounting and Economics, 1982. 4(2): p. 85107.

[4] Womack, K.L., Do brokerage analysts' recommendations have investment value? The Journal of Finance, 1996. 51(1): p. 137-167.

[5] Asquith, P., M.B. Mikhail, and A.S. Au, Information content of equity analyst reports. Journal of Financial Economics, 2005. 75(2): p. 245-282.

[6] Barth, M.E., R. Kasznik, and M.F. McNichols, Analyst coverage and intangible assets. Journal of Accounting Research, 2001. 39(1): p. 1-34.

[7] Lehavy, R., F. Li, and K. Merkley, The Effect of Annual Report Readability on Analyst Following and the Properties of Their Earnings Forecasts. Accounting Review, 2011. 86(3): p. 1087-1115.

[8] Hugon, A. and V. Muslu, Market demand for conservative analysts. Journal of Accounting \& Economics, 2010. 50(1): p. 42-57.

[9] Bonner, S.E., A. Hugon, and B.R. Walther, Investor reaction to celebrity analysts: The case of earnings forecast revisions. Journal of Accounting Research, 2007. 45(3): p. 481-513.

[10] Lawrence, A., J.P. Ryans, and E.Y. Sun, Investor demand for sell-side research. Accounting Review, 2017. 92(2): p. 123-149.

[11] Chen, H., et al., Wisdom of crowds: The value of stock opinions transmitted through social media. Review of Financial Studies, 2014. 27(5): p. 1367-1403.

[12] Jame, R., et al., The value of crowdsourced earnings forecasts. Journal of Accounting Research, 2016. 54(4): p. 1077-1110.

[13] Breitmayer, B., F. Massari, and M. Pelster, Swarm intelligence? Stock opinions of the crowd and stock returns. International Review of Economics \& Finance, 2019. 64: p. 443-464. 
[14] Clarke, J., et al., Fake news, investor attention, and market reaction. Information Systems Research, 2020. 32(1): p. 35-52.

[15] Kahneman, D., Attention and effort. Vol. 1063. 1973: Citeseer.

[16] DellaVigna, S. and J.M. Pollet, Investor inattention and Friday earnings announcements. Journal of Finance, 2009. 64(2): p. 709-749.

[17] Hirshleifer, D., S.S. Lim, and S.H. Teoh, Driven to distraction: Extraneous events and underreaction to earnings news. Journal of Finance, 2009. 64(5): p. 22892325.

[18] Louis, H. and A. Sun, Investor inattention and the market reaction to merger announcements. Management Science, 2010. 56(10): p. 1781-1793.

[19] Peng, L. and W. Xiong, Investor attention, overconfidence and category learning. Journal of Financial Economics, 2006. 80(3): p. 563-602.

[20] van der Heijden, A.H., Selective attention in vision. 2003: Routledge.

[21] Huang, A.H., A.Y. Zang, and R. Zheng, Evidence on the information content of text in analyst reports. Accounting Review, 2014. 89(6): p. 2151-2180.

[22] Welch, I., Herding among security analysts. Journal of Financial Economics, 2000. 58(3): p. 369-396.

[23] Graham, J.R., Herding among investment newsletters: Theory and evidence. Journal of Finance, 1999. 54(1): $\mathrm{p}$. 237-268.

[24] Palmon, D., B. Sarath, and H.C. Xin, Bold stock recommendations: Informative or worthless? Contemporary Accounting Research, 2020. 37(2): p. 773-801.

[25] Lerman, A., Individual investors' attention to accounting information: Evidence from online financial communities. Contemporary Accounting Research, 2020. 37(4): p. 2020-2057.

[26] Conrad, J., B. Cornell, and W.R. Landsman, When is bad news really bad news? Journal of Finance, 2002. 57(6): p. 2507-2532.

[27] Da, Z. and X. Huang, Harnessing the wisdom of crowds. Management Science, 2020. 66(5): p. 1847-1867.

[28] Clement, M.B. and S.Y. Tse, Financial analyst characteristics and herding behavior in forecasting. Journal of Finance, 2005. 60(1): p. 307-341.

[29] Gleason, C.A. and C.M. Lee, Analyst forecast revisions and market price discovery. Accounting Review, 2003. 78(1): p. 193-225.

[30] Xu, N., et al., Analyst herding and stock price crash risk: evidence from China. Journal of International Financial Management \& Accounting, 2017. 28(3): p. 308-348.

[31] Hirshleifer, D., et al., Decision fatigue and heuristic analyst forecasts. Journal of Financial Economics, 2019. 133(1): p. 83-98.

[32] Driskill, M., M.P. Kirk, and J.W. Tucker, Concurrent earnings announcements and analysts' information production. Accounting Review, 2020. 95(1): p. 165-189.

[33] Falkinger, J., Limited attention as a scarce resource in information - rich economies. The Economic Journal, 2008. 118(532): p. 1596-1620.

[34] Miller, G.A., The magical number seven, plus or minus two: Some limits on our capacity for processing information. Psychological Review, 1994. 63(2): p. 8197.

[35] DellaVigna, S. and J.M. Pollet, Demographics and industry returns. American Economic Review, 2007. 97(5): p. 1667-1702.

[36] Cohen, L. and A. Frazzini, Economic links and predictable returns. Journal of Finance, 2008. 63(4): p. 1977-2011.

[37] Hirshleifer, D. and S.H. Teoh, Limited attention, information disclosure, and financial reporting. Journal of Accounting \& Economics, 2003. 36(1-3): p. 337-386.

[38] Frederickson, J.R. and L. Zolotoy, Competing Earnings Announcements: Which Announcement Do Investors Process First? Accounting Review, 2016. 91(2): p. 441462.

[39] Fiske, S.T. and S.E. Taylor, Social cognition. 1991: Mcgraw-Hill Book Company.

[40] Barberis, N., A. Shleifer, and R. Vishny, A model of investor sentiment. Journal of Financial Economics, 1998. 49(3): p. 307-343.

[41] Ito, T.A., et al., Negative information weighs more heavily on the brain: The negativity bias in evaluative categorizations. Journal of Personality and Social Psychology, 1998. 75(4): p. 887-900.

[42] Baumeister, R.F., et al., Ego depletion: Is the active self a limited resource? Journal of Personality and Social Psychology, 1998. 74(5): p. 1252-1265.

[43] Marquaridt, D.W., Generalized inverses, ridge regression, biased linear estimation, and nonlinear estimation. Technometrics, 1970. 12(3): p. 591-612.

[44] Hair, J.F., et al., Multivariate data analysis. Vol. 5. 1998: Prentice hall Upper Saddle River, NJ.

[45] Cohen, J., et al., Applied multiple regression/correlation analysis for the behavioral sciences. 2013: Routledge.

[46] Kadous, K., M. Mercer, and J. Thayer, Is there safety in numbers? The effects of forecast accuracy and forecast boldness on financial analysts' credibility with investors. Contemporary Accounting Research, 2009. 26(3): p. 933-968.

[47] Sicherman, N., et al., Financial attention. Review of Financial Studies, 2016. 29(4): p. 863-897.

[48] Drake, M.S., D.T. Roulstone, and J.R. Thornock, The determinants and consequences of information acquisition via EDGAR. Contemporary Accounting Research, 2015. 32(3): p. 1128-1161.

[49] Barber, B.M. and T. Odean, All that glitters: The effect of attention and news on the buying behavior of individual and institutional investors. Review of Financial Studies, 2008. 21(2): p. 785-818.

[50] Seasholes, M.S. and G. Wu, Predictable behavior, profits, and attention. Journal of Empirical Finance, 2007. 14(5): p. 590-610.

[51] Gervais, S., R. Kaniel, and D.H. Mingelgrin, The high - volume return premium. Journal of Finance, 2001. 56(3): p. 877-919.

[52] Da, Z., J. Engelberg, and P.J. Gao, In search of attention. Journal of Finance, 2011. 66(5): p. 1461-1499. 